\title{
AS CRIANÇAS RIBEIRINHAS E O RITO DO BANHO DE RIO
}

Cristiane do Socorro Gonçalves Farias ${ }^{1}$

Ao fazermos o percurso de um rio durante uma pesquisa podemos perceber a relação dos vários atores sociais com o meio no qual estão inseridos, aqui no caso, o rio e as matas. A presença das crianças é muito forte, principalmente na hora da brincadeira no rio, a hora do banho no rio. Não como um rito obrigatório, mas como algo que sempre acontece da mesma maneira, sem tornar-se obrigação para eles, um acontecimento natural.

$\mathrm{O}$ rio, que é fonte de alimento, lugar de enchentes e vazantes que levam os adultos a buscarem o pão nosso de cada dia. No entanto, não é somente lugar de labor, lugar de pesos do trabalho. O rio é brincalhão. As águas muitas vezes são leves, suspensas de problemas e de lamentos. Se toda a criança, desde o ventre de sua mãe, já tem intimidade com as águas, pois estão envoltas no líquido que as permitem viver, o que dizer das crianças que nascem dos ventres que se banham todos os dias nos rios? Margaret Mead (apud COHN, 2005,14) firma que "crianças existem em toda parte, e por isso podemos estudá-las comparando suas experiências e vivências; mas essas experiências e vivências são diferentes para cada lugar, e por isso temos que entendê-las em seu contexto sociocultural".

As águas, que já alimentam as crianças em suas andanças de casco pelo rio, como alimentava Biá, personagem da obra literária Chão de Lobos de Dalcídio Jurandir ${ }^{2}$, nos retornos da escola, e que ainda não entendia a diferença social em que vivia: "Biá voltando remando, apanhava pelo rio algum taperebá que ia roendo, roendo", é a mesma para muitas crianças hoje, nos revela que apesar das dificuldades, a criança ainda está ali. A criança apresenta a inocência e a pureza, associando às aguas, assim como para Bachelard (2013) as “águas primaveris" possuem “o frescor”, pois "ela embala como uma mãe". Possuem o frescor e a segurança ao comparar o embalo de uma mãe com os

\footnotetext{
${ }^{1}$ Mestra em Linguagens e Saberes na Amazônia. Universidade Federal do Pará. Campus Universitário de Bragança.Email: kissfarias@hotmail.com

22 In: Chão de Lobos. Rio de Janeiro, Record, 1976. Texto retirado do livro Texto e Pretexto: Experiência de educação contextualizada a partir da literatura feita por autores amazônicos, de Fares et all. vol.I CEJUP,1992.
} 
embalos da água, As águas aqui nesse momento são para mim, as águas calmas que embalam as crianças a se jogarem, literalmente, em seus leitos, realizando mergulhos muito profundos.

O momento do mergulho é o momento do silêncio, nada se escuta a não ser o coração, o corpo fica de bubuia entre as águas: sutil flutuação, dono do mundo, tudo se pode fazer, quase peixe, quase boto, quase cobra, por uns instantes eternos, somos seres pertencentes àquelas águas. Parecidos com Missunga de Dalcídio (2008), que imaginava os seres dormindo no fundo. E o devaneio infantil perdura até o momento em que a falta de oxigênio manda emergir. É necessário estarmos atentos e entendê-las, e ao mundo que as rodeia, pois, "as crianças não são apenas produzidas pelas culturas, mas também produtoras de cultura. Elas elaboram sentidos para o mundo e suas experiências compartilhando plenamente de uma cultura" (COHN, 2005, p.16). Precisamos estar abertos para entender a dimensão do envolvimento das crianças ribeirinhas com todo o meio que as envolvem, céu, floresta e rio. Essas crianças já nascem predispostas a serem íntimas das águas.

Primeiro, aprendem a entrar nelas para acontecer a relação de confiança. A partir daí as primeiras nadadas, os primeiros mergulhos perto do trapiche, até conseguirem, sozinhas, mergulhar e aprender a voltar, não existe mais medo é somente a vontade de estar ali, uma espécie de "inocência e contemplação íntima” Bachelard (23: 2013).

Rio e crianças, crianças e rios. A hora do banho é a hora do encontro, do grande falatório, hora de mexer com a s águas, parecem brincarem juntas. É hora de quem sabe nadar ensinar quem não sabe a hora das melhores brincadeiras. E as primeiras braçadas vão sendo treinadas. Crianças chegam de todas as casas: uma, mais uma, e mais e mais e tudo está perfeito. E começam-se as brincadeiras: pega-pega, pira-pega, luta, quem demora mais no fundo ${ }^{3}$. Mergulha-se. Mas o lugar para boiar ninguém se atreve a adivinhar, a água lhe deixa invisível Mas para os maiores, a preferida é o salto. Procurase a ponto mais alto que os distancie das águas para impressionar. A hora dos pulos espetaculares, onde o saltador é a atração, a plateia é garantida. A melhor hora do dia. Não tem escola, não tem tarefa, não tem nada, é só o corpo e as águas.

As brincadeiras dentro e fora das águas são todas carregadas de simbolismo, por isso "seremos menos capazes de entender o que elas fazem nessas brincadeiras se não

\footnotetext{
${ }^{3}$ Nome dado às brincadeiras. Primeiro vota-se em um, que vai em seguida tentar pegar o segundo. E então, a tarefa de pegar uma outra pessoa passa a ser deste, e assim sucessivamente até não terem mais fôlego.
}

Nova Revista Amazônica - ANO IV - Volume 3 - DEZEMBRO 2016 - ISSN: 2318-1346 
entendermos a simbologia que as embasam, e essa simbologia extrapola o mundo das crianças" (COHN). As águas vazantes junto com o chamado das mães avisando a hora da saída. Hora triste e de frio. A saída é forçada. Dessa saída já contava, com muita simplicidade, Celina (1997, p, 130) ao afirmar que "para nós, crianças, ô farra, só saímos do igarapé aos ralhos, de beiço roxo, dedos engelhados e dormentes, a água era um gelo".

Depois da saída as águas voltam à calmaria e seguem seu percurso...

\section{REFERÊNCIAS}

BACHELARD, Gaston. A água e os sonhos: ensaio sobre a imaginação da matéria. Trad Antonio e Pádua Danesi. -2a ed. São Paulo: Editora WMF Martins Fontes,2013.

COHN, Clarice. Antropologia da criança. $2^{\mathrm{a}}$ ed. ZAHAR.

JURANDIR, Dalcídio. Marajó. - 4. ed.- Belém: EDUFPA; Rio de Janeiro; Casa Rui Barbosa, 2008. Coleção Ciclo do extremo Norte) 


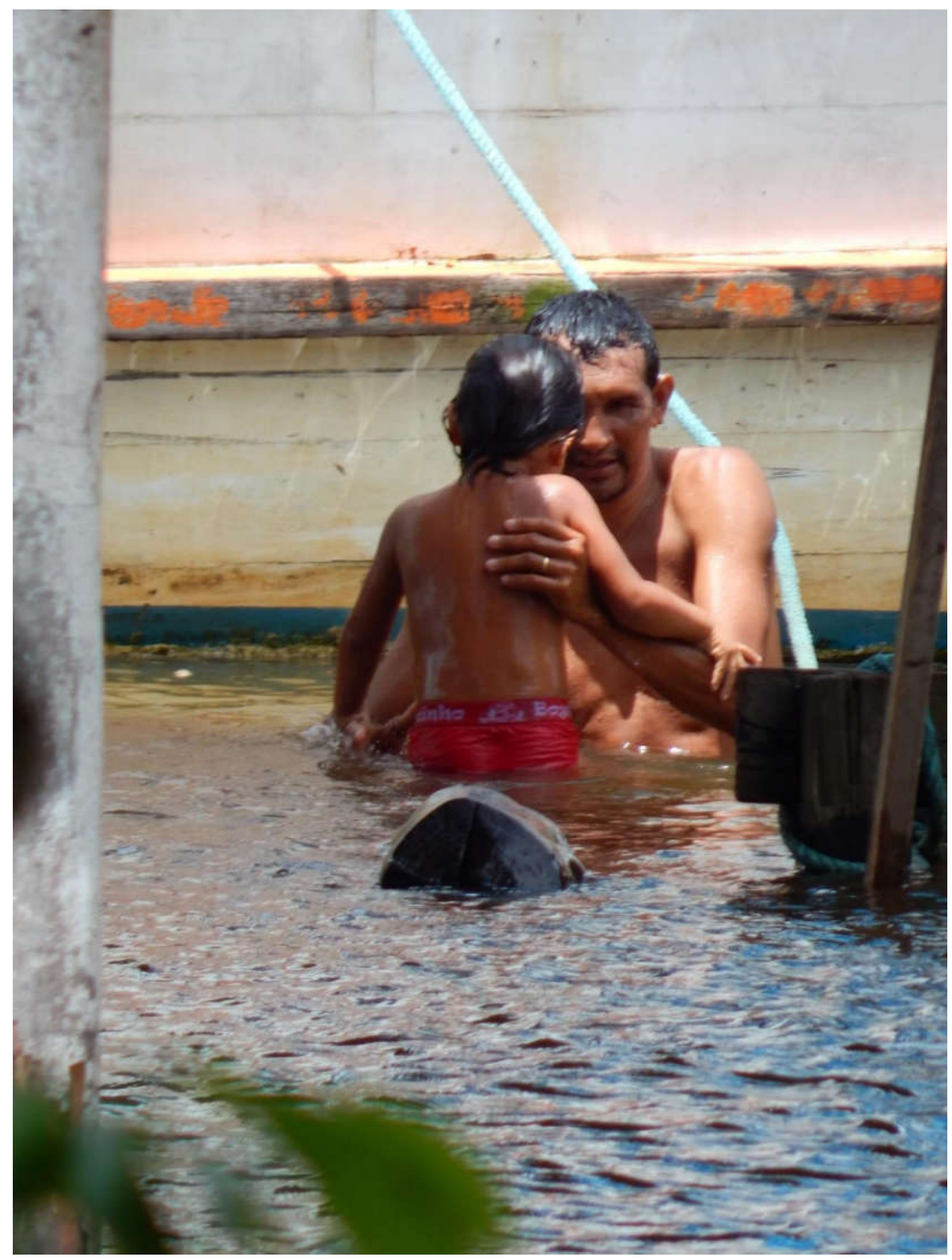



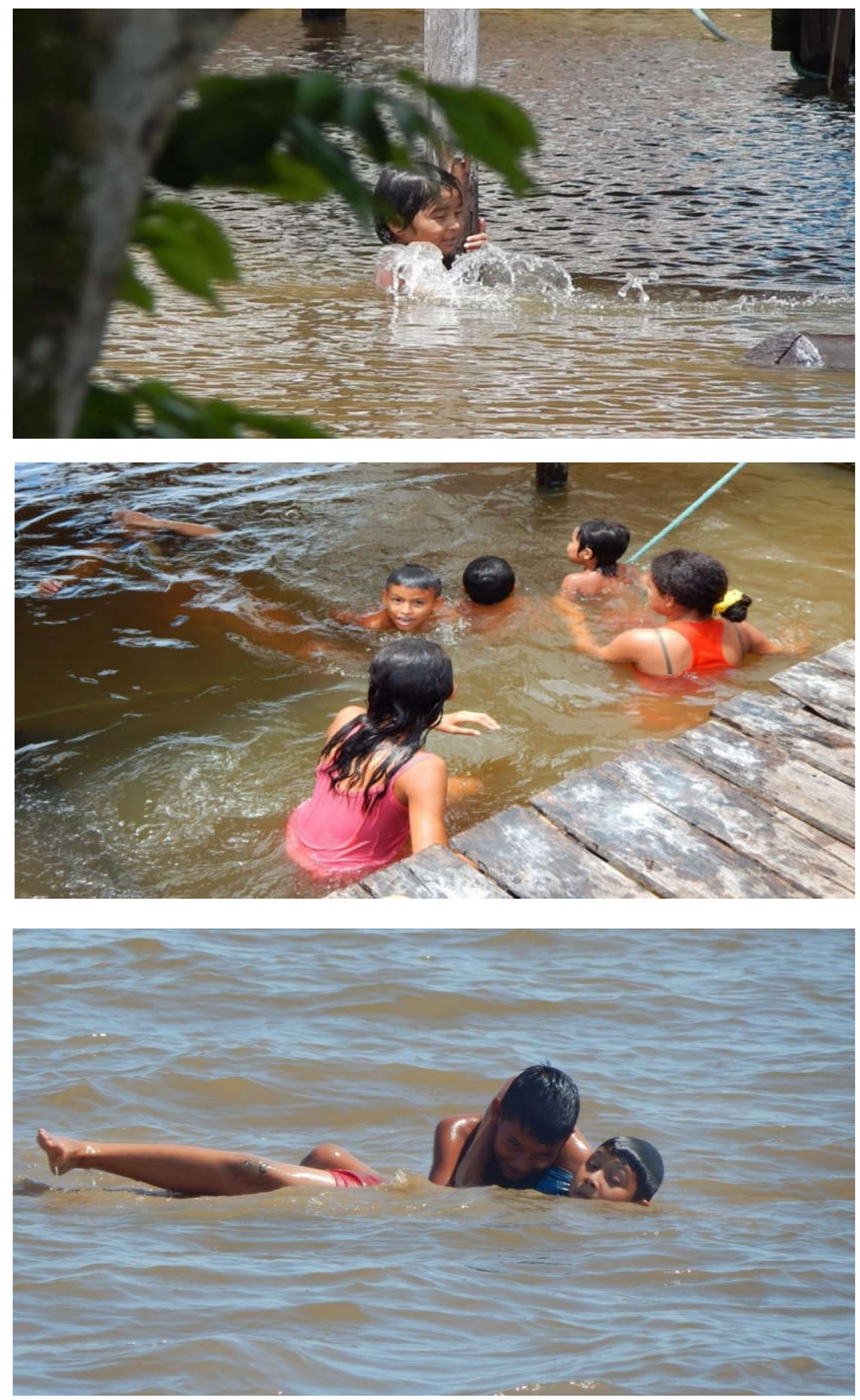


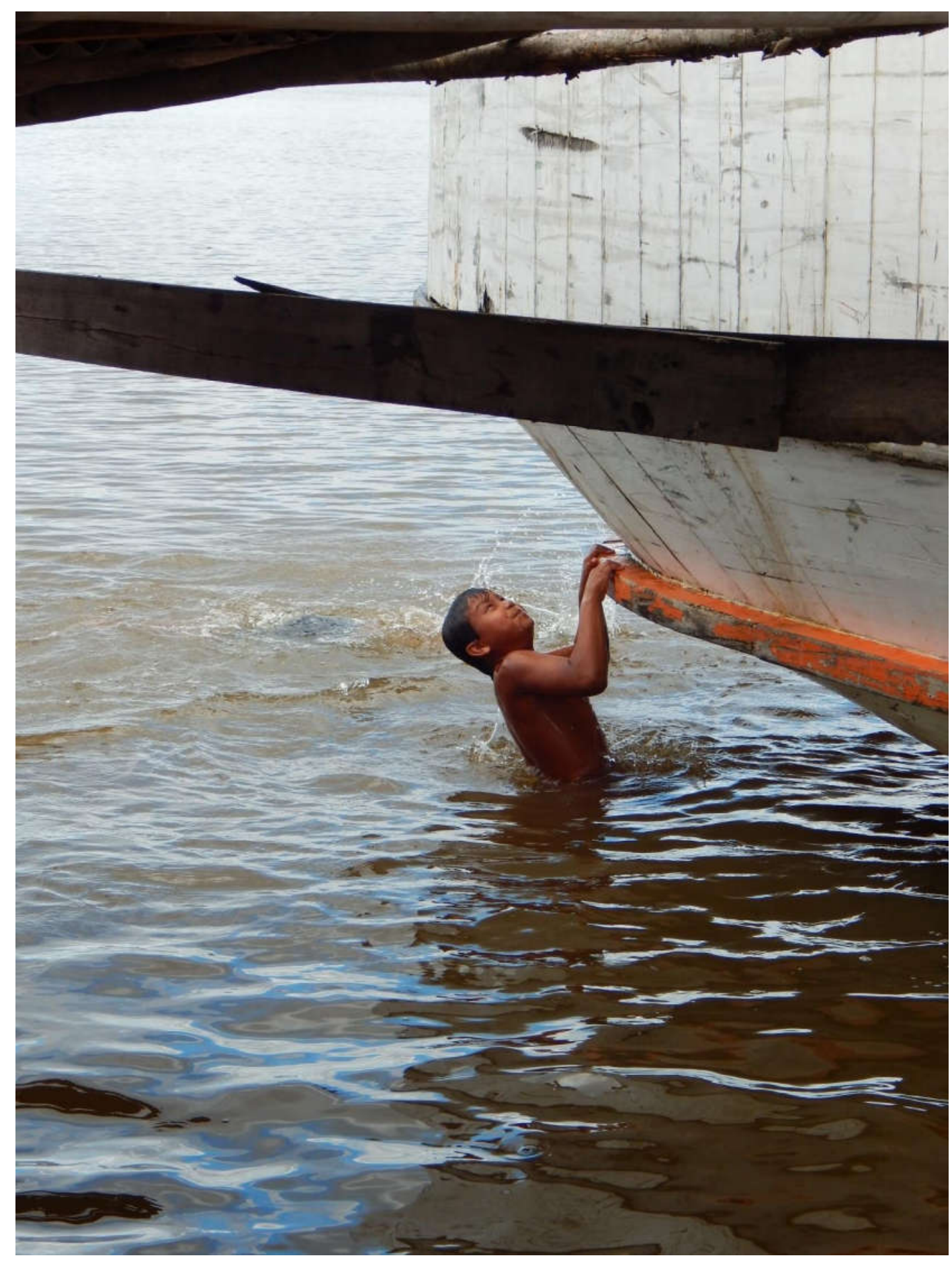




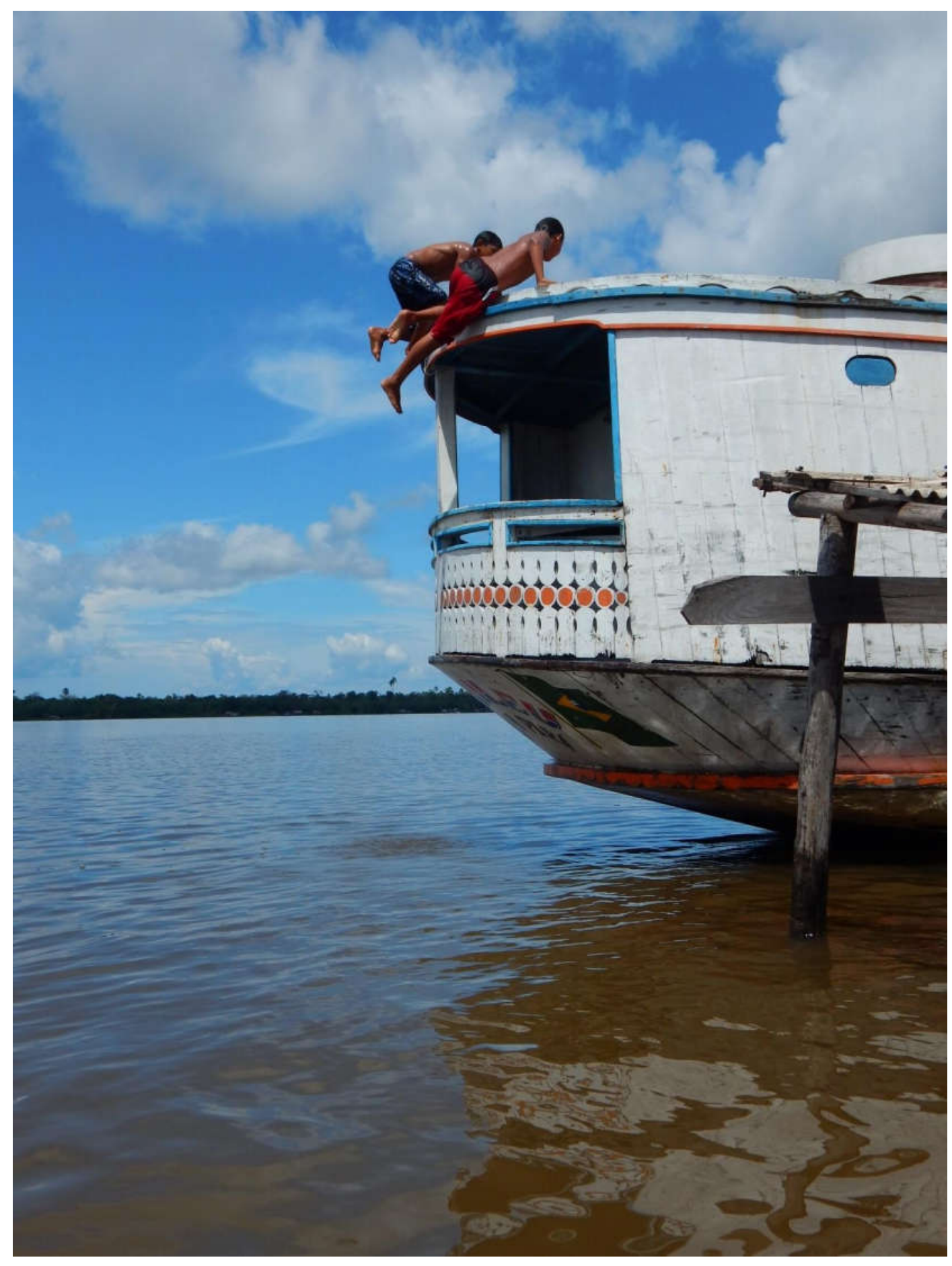



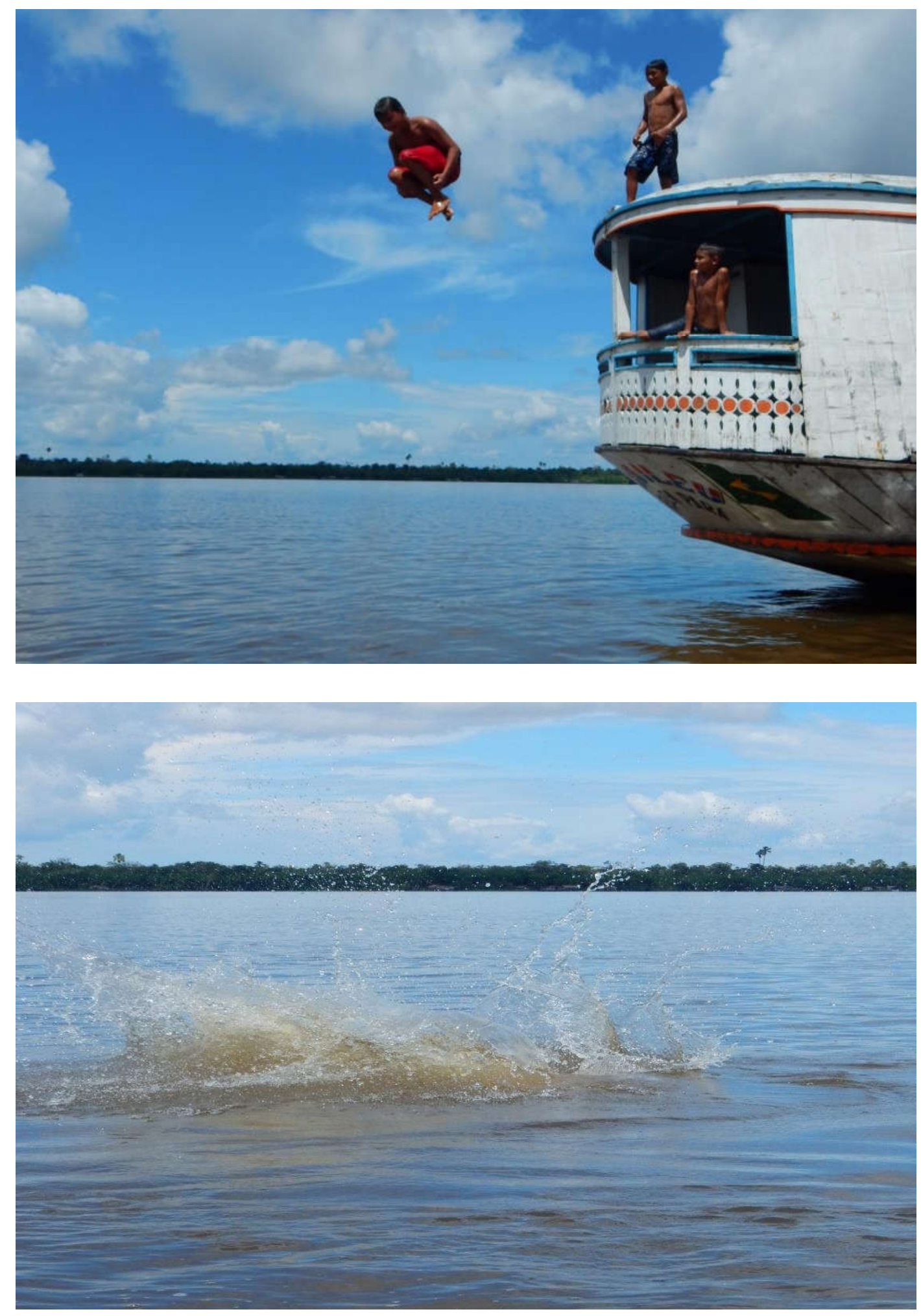


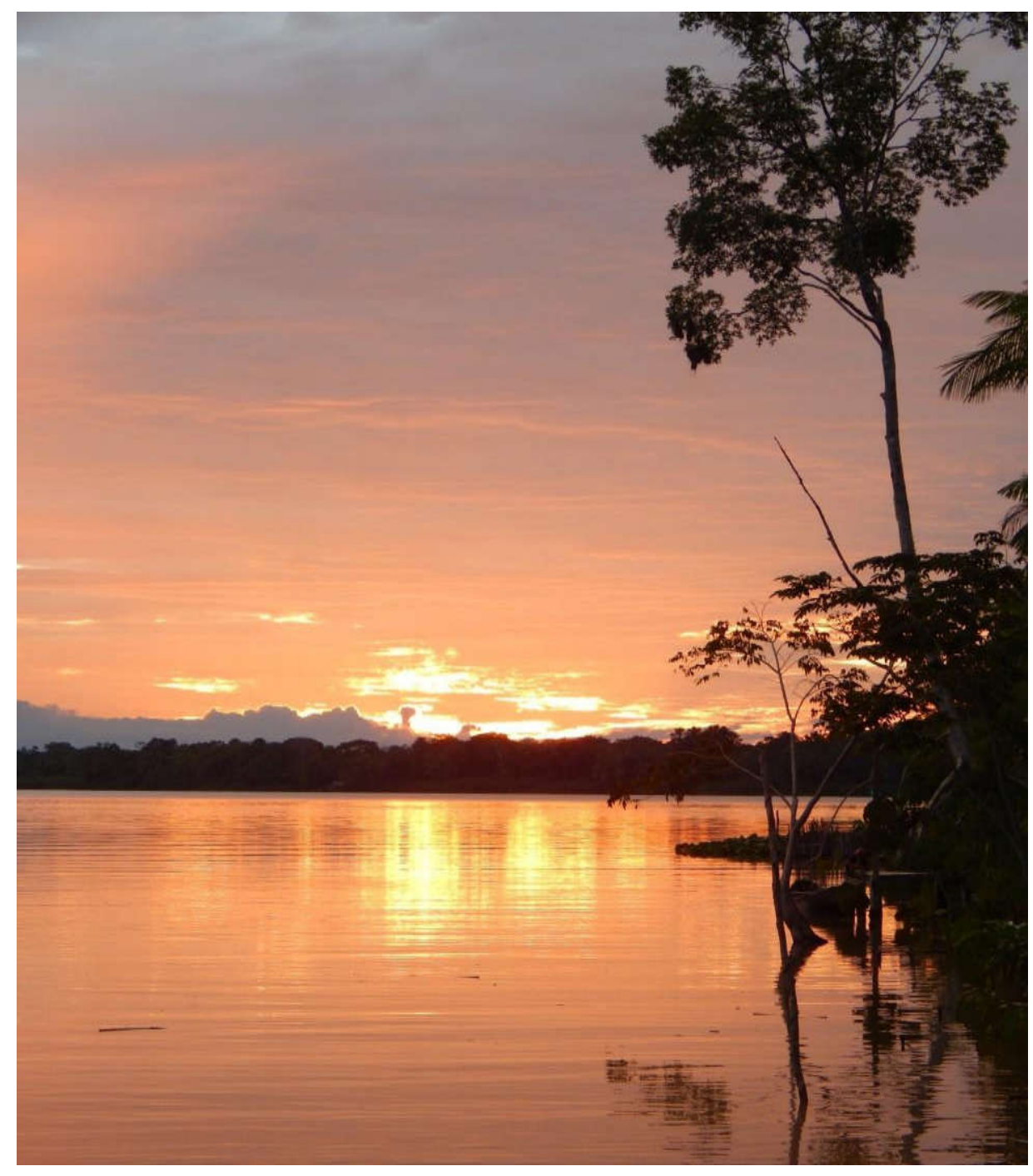

